\title{
Valorization of Renewable Carbon Resources for Chemicals
}

\author{
Xi Chen, Bin Zhang, Yunzhu Wang, and Ning Yan*
}

\begin{abstract}
The overuse of fossil fuels has caused an energy crisis and associated environment issues. It is desirable to utilize renewable resources for the production of chemicals. This review mainly introduces our recent work on the transformation of renewable carbon resources including the conversion of cellulose, lignin, and chitin into sustainable chemicals. Various transformation routes have been established to form value-added chemicals, and accordingly a variety of effective catalytic systems have been developed, either based on metal catalysis and/or acid-base catalysis, to enable the desired transformation.
\end{abstract}

Keywords: Biomass · Catalysis · Cellulose $\cdot$ Chitin · Lignin · Renewable chemicals

\section{Introduction}

Due to the slow but inevitable depletion of fossil oils, a significant research effort is being made to seek for renewable alternatives. ${ }^{[1-4]}$ The future chemical industry will eventually evolve into a new, sustainable pattern, starting with inexpensive, green and renewable resources. Biomass materials are promising feedstock for the future chemical industry because they are organic, abundant, highly functionalized and renewable. Valorization of biomass has a long-standing history dating back to the fermentation of starch to produce ethanol, however, biomass resources such as starch, protein and many lipids are the major foods of humans and thus not ideal for chemical and fuel production. On the other hand, lignocellulosic biomass constituting of cellulose, hemicellulose and lignin, usually forms urban or agricultural wastes (straws, sugar canes, barks, etc.). ${ }^{[5-7]}$ These non-edible lignocellulosic biomass are regarded as the most promising alternative feedstock and currently un- der extensive investigation. ${ }^{[8-10]}$ Besides, ocean-based chitin biomass also fits the demand as a resource. Chitin, which is the major component in the shells of the crabs and shrimps, is the world's second abundant biomass next to cellulose; [11-13] it is an ideal resource for the production of $\mathrm{N}$-containing chemicals due to its biologically fixed nitrogen content.

Biomass resources are highly functionalized, oxygen-enriched polymers (structures shown in Fig. 1). Cellulose is a linear polymer consisting of $\beta(1 \rightarrow 4)$ linked D-glucose units with high crystallinity accounting for 50-70 wt\% of lignocellulosic biomass, and is the primary cell wall of plants. ${ }^{22}$ The structure of chitin resembles that of cellulose, with the only difference on the $\mathrm{C}(2)$ position where an acetyl amide group replaces the hydroxyl group. Chitin possesses a higher crystallinity and is even more difficult to convert or dissolve than cellulose. Lignin, which is an integral part of the secondary cell walls of plants ${ }^{[14]}$ (10-30 wt \%), is the most robust component of lignocellulosic biomass. Lignin is a cross-linked, aromatic and complex polymer consisting of hetero-units, which is often directly burned for heat. ${ }^{[15]}$

The valorization of these carbon resources can transform waste into valuable chemicals, leading to both economic and environmental benefits to a modern society. There are many excellent reviews on the conversion of cellulose, lignin, and chitin, and therefore the scope of this review is on the works relevant to our group in the field.

\section{Cellulose Conversion}

At present, cellulose conversion has been investigated most widely and a plethora of research and review papers are published on the topic. ${ }^{[16-20]}$ 5-(hydroxymethyl)furfural (5-HMF) is a highly valued platform chemical of cellulose for a series of other fine chemicals. ${ }^{[21]}$ In an attempt to replace the crude-oil based polyethylene terephthalate (PET) by biobased feedstock, a new conversion route

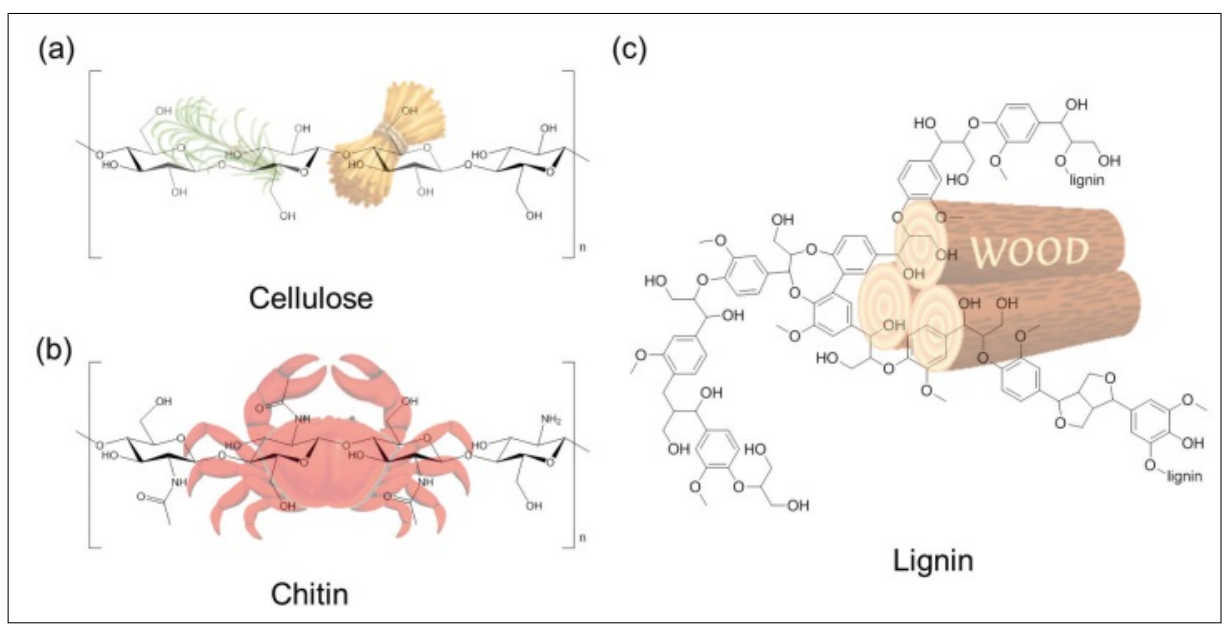

Fig. 1. The chemical structures of (a) cellulose, (b) chitin and (c) lignin. 
starting from cellulose has been envisaged (Scheme 1). The first step is the catalytic conversion of cellulosic biomass materials, either directly or via glucose and/ or fructose, into 5-HMF. Subsequently, 5 -HMF is oxidized over a metal catalyst by air into 2,5-furandicarboxylic acid (FDCA), which is one of the key building blocks for a renewable plastic. In parallel, hydrogenolysis of cellulose provides ethylene glycol as the other building block. Copolymerization of ethylene glycol and FDCA affords polyethylene furanoate (PEF) - an ideal replacement for PET, ${ }^{[22]}$ which is an industrially important polymer with $15 \mathrm{Mt} / \mathrm{yr}$ capacity worldwide.[23]

Ionic liquids (ILs) were found to be highly suitable and effective solvents in biomass conversion due to the high solubility toward highly functionalized biomass components. ${ }^{[24]}$ The enhanced conversion of glucose and cellulose into 5-HMF was demonstrated by rational design of IL solvents with $\mathrm{CrCl}_{2}$ as the catalyst.[25] The role of $\mathrm{CrCl}_{2}$ in glucose isomerization to fructose in 1-ethyl-3-methylimidazolium chloride ([Emim]Cl) solvent was welldocumented.[26] Imidazolium-based ILs with different cations were synthesized as the solvent, which possess a higher degree of 3D structural pattern than other ILs due to the ability to orderly direct with the aid of hydrogen bonds formed among the three acidic hydrogen atoms on the imidazolium cation. ${ }^{[24]}$ We speculated that the incorporation of particular hydrogen bond donor/ acceptor groups, and potentially other kinds of functionality, should promote the interaction between biomass substrate and the IL. To test the hypothesis, nine IL solvents including [Emim] $\mathrm{Cl}$ and the modified IL with various ether- and hydroxylfunctionalized imidazolium chlorides were evaluated (Fig. 2). IL 4 showed the best performance with $65 \%$ yield starting from glucose and was further studied in a IL/organic co-solvent system. It was found that toluene was a beneficial co-solvent, which improved the yield to $75 \%$. As a result, a new bifunctionalized IL 9 was synthesized based on IL $\mathbf{4}$, by changing its methyl group into a $\mathrm{CH}_{2} \mathrm{CH}_{2} \mathrm{Ph}$ group. An enhanced yield of $81 \%$ was achieved by using IL $\mathbf{4}$ and $\mathbf{9}$ as the solvent (1:9, $\mathrm{w} / \mathrm{w}$ ), and the solvent system was recyclable. The mechanism was investigated in detail by nuclear magnetic resonance (NMR) spectroscopy and density functional theory (DFT) calculations. First, the $\mathrm{CrCl}_{2}$-IL 4 adduct was obtained and characterized by X-ray crystallography. The computer calculations suggested that the replacement of the $\left[\mathrm{C}_{2} \mathrm{OHmim}\right]^{+}$ligand by glucose is remarkably energy-favorable to initiate the reaction. The promoting effect of toluene was also identified. The $\mathrm{CrCl}_{2}$ IL 4 adduct could reversibly form a weak

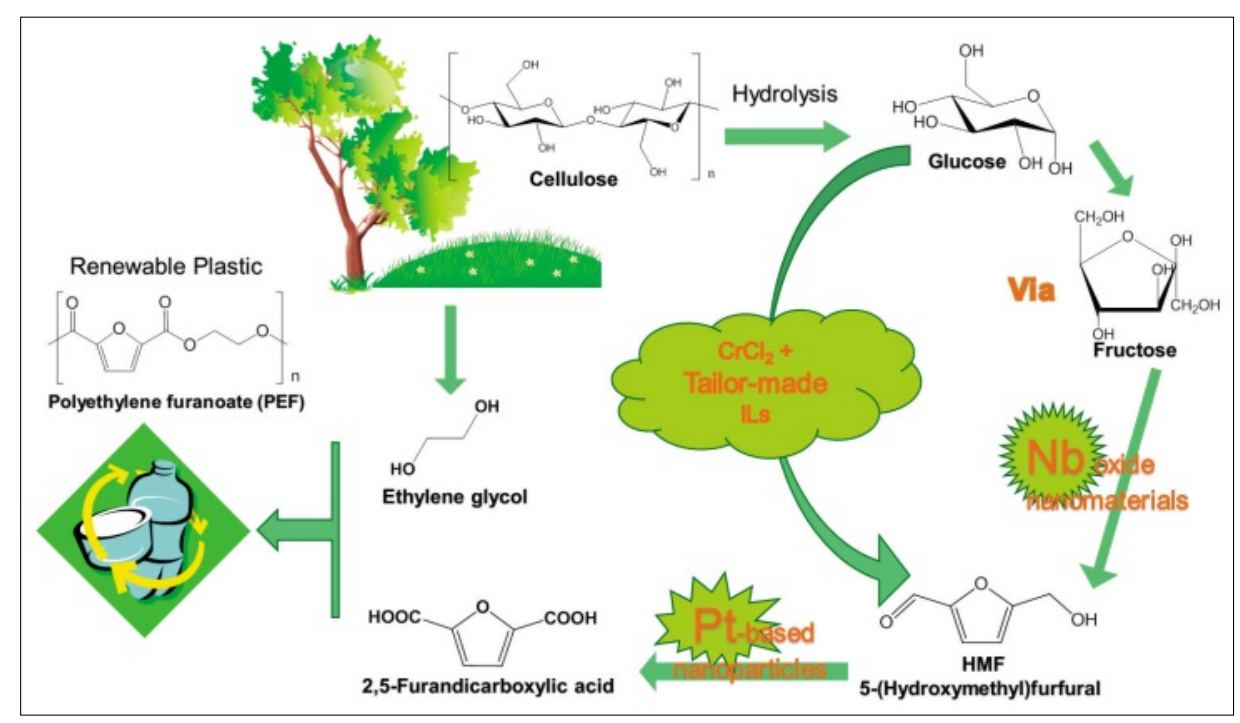

Scheme 1. Conversion routes to a renewable plastic material, PEF, from cellulose. complex with toluene, which stabilizes the catalyst and prevent deactivation. NMR studies showed consistent results with the DFT calculations. Glucose forms hydrogen bonds with the IL ring protons and positions, and the intense hydrogen bond possibly activates the glucose to a larger extent.

Although 5-HMF production from biomass has been widely investigated by using catalysts such as organic acids, mineral acids and ionic liquids, ${ }^{[27-29]}$ recyclable solid acid catalysts are highly desirable. The formation of 5-HMF from fructose and inulin by using sulfated, mesoporous niobium oxide (MNO-S) catalyst has been studied recently in dimethyl sulfoxide (DMSO) solvent.[30] The synthesis of MNO is a novel, simple and low cost protocol and the MNO-S could be easily obtained by functionalization with sulfate anions. The structures of the catalyst were comprehensively characterized and compared with the commercial $\mathrm{Nb}_{2} \mathrm{O}_{5}$ catalyst by scanning electron microscope (SEM), X-ray diffraction (XRD), X-ray photoelec$-\mathrm{OH}$ group through $\mathrm{C}(6), \mathrm{C}(5)$ and $\mathrm{C}(1)$ tron spectroscopy (XPS) and BrunauerEmmett-Teller (BET) analysis. The synthesized MNO-S catalyst showed superior performance to the commercial one and other solid acids such as Amberlyst-15, Amberlyst IR 120, Nafion NR50 and sulfated zirconium oxide $\left(\mathrm{ZrO}_{2}\right)$ due to the much enhanced surface area and acidity. The surface area of commercial $\mathrm{Nb}_{2} \mathrm{O}_{5}$ was as low as $2.1 \mathrm{~m}^{2} / \mathrm{g}$, whereas the surface area of MNO-S can be as high as $131 \mathrm{~m}^{2} / \mathrm{g}$. The acid strengths of the catalysts were examined by pyridine adsorption and subsequent FTIR spectroscopy. The absorption associated with Brønsted acid sites could be easily identified for MNO-S catalysts calcined at different temperatures, revealing that the acid strength decreased with the increase of temperature. In agreement with the characterization results, MNO-S showed the best performance in the catalytic tests. $88 \%$ yield of 5 -HMF could be achieved from fructose at $120^{\circ} \mathrm{C}$ in DMSO for $5 \mathrm{~h}$. Recyclability tests were conducted and the reactivity was decreased only slightly after four cycles. The weight of the recovered catalyst remained almost

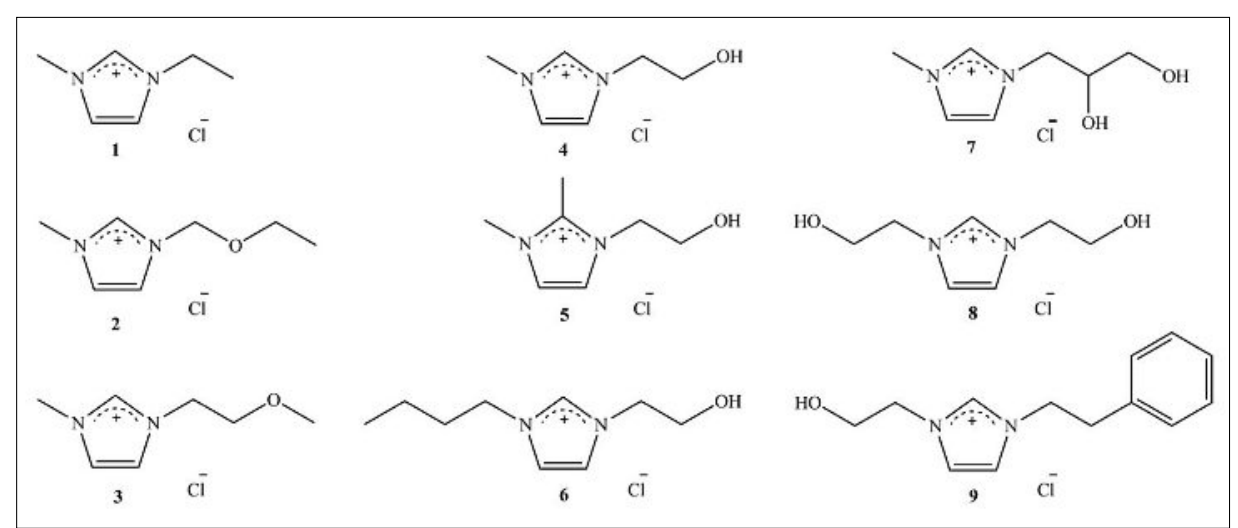

Fig. 2. The structures of ILs evaluated in 5-HMF formation from glucose and other sugars.

Reproduced from ref. [25] with the permission. 
unchanged after the recycling, which suggested that negligible leaching occurred. Nevertheless, the recyclability tests with MNO-S calcined at different temperatures revealed that catalyst leaching did occur for MNO-S calcined at low temperature such as $100{ }^{\circ} \mathrm{C}$, suggesting that the catalyst calcined at higher temperature to be more stable. The acid sites on the catalyst are capable to catalyze both hydrolysis and dehydration reactions in a one-pot manner, and inulin could be directly converted into 5 -HMF with $60 \%$ yield at $110{ }^{\circ} \mathrm{C}$ for $5 \mathrm{~h}$ in DMSO. However, glucose and cellulose can only be partially converted under the same catalytic systems.

The subsequent oxidation of 5-HMF into FDCA was demonstrated by using platinum nanoparticles (Pt NPs) stabilized by polyvinylpyrrolidone (PVP) in water with molecular oxygen. ${ }^{[31]}$ Water-dispersed Pt NPs can readily oxidize 5-HMF into FDCA under mild reaction conditions. PtPVP-GLY NPs were synthesized by first dissolving the $\mathrm{H}_{2} \mathrm{PtCl}_{6}$ precursor in ethylene glycol (EG) and then adding $\mathrm{NaOH}$ to give an orange-yellow solution, followed by heating at $145^{\circ} \mathrm{C}$ under $\mathrm{N}_{2}$ for $3 \mathrm{~h}$. PVP was added after cooling and the mixture was dialyzed comprehensively. Five different sizes of Pt NPs were prepared by a seeded growth method in which the PtPVP-GLY NPs were adopted as the seeds in the initial stage. It was observed that the increase of particle size would decrease the activity, which is typical in metal NP catalysis. The Pt NPs with an average particle size of $1.5 \mathrm{~nm}$ afforded FDCA in $95 \%$ yield after $24 \mathrm{~h}$ at $80{ }^{\circ} \mathrm{C}$ under 1 bar $\mathrm{O}_{2}$. Kinetic studies suggest that the oxidation of the $-\mathrm{CH}_{2} \mathrm{OH}$ group in the starting material to the -CHO group in 2,5-diformylfuran (DFF) is facilitated by Pt NPs with larger size, however, the further oxidation of the $-\mathrm{CHO}$ group in DFF to the $-\mathrm{COOH}$ group in 5-formyl-2-furancarboxylic acid(FFCA) is preferably catalyzed by the smaller NPs. Following that, since NP stabilizers can have considerable influence on the catalytic performance of solvent-dispersed NPs, the PVP was replaced by an ionic polymer (IP), poly-1,3-bis(4-vinylbenzyl) imidazolium chloride (poly[bvbim]Cl) as the stabilizer. The IP forms porous structures in the solid state and is notably stable as well as insoluble in water. ${ }^{[32]}$ The obtained NPs have an average particle size of $2.0 \mathrm{~nm}$ and afforded FDCA over $99 \%$ yield under identical conditions. The kinetic modelling was conducted and an increased overall rate was observed. The role of $\mathrm{O}_{2}$ was further investigated by using $\mathrm{H}_{2}{ }^{18} \mathrm{O}$, and the reaction cycle was proposed (Scheme 2). Overall, it was also disclosed that ${ }^{18} \mathrm{O}$ is incorporated into the HMF starting material, which is followed by addition of one ${ }^{18} \mathrm{O}$ atom in each reaction step.

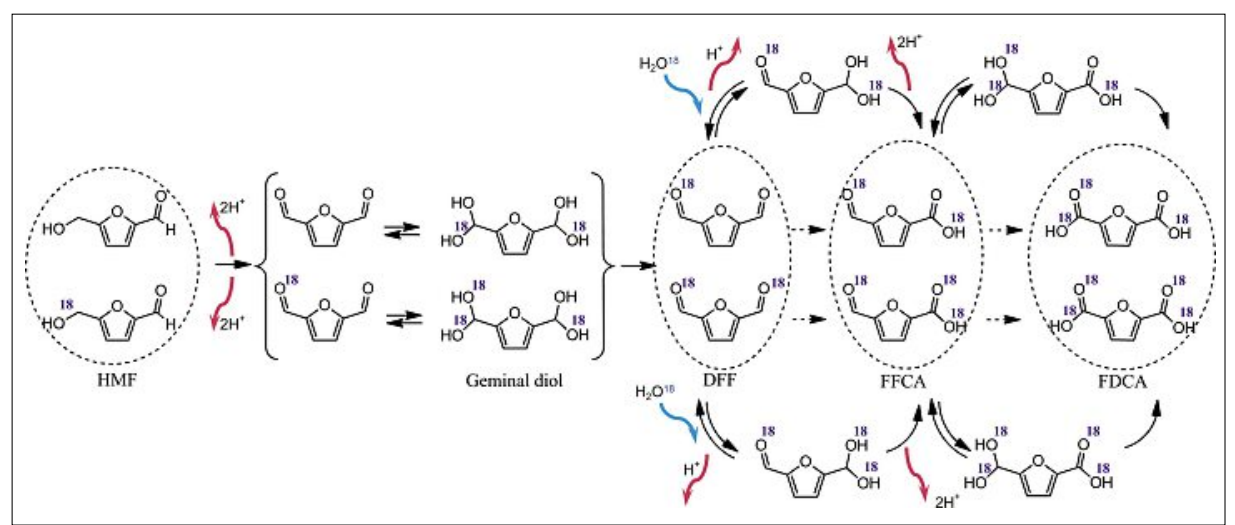

Scheme 2. Incorporation of ${ }^{18} \mathrm{O}$ in the reaction steps: ${ }^{18} \mathrm{O}$ (blue) and observed units in dashed ellipses. Reproduced from ref. [31] with permission.

\section{Lignin Conversion}

The conversion of lignin has huge potential for the sustainable manufacturing of aromatic fine chemicals. The pioneering paper of lignin depolymerization can be dated to 1938 and copper-chromite catalysts with high-loading were used under harsh reaction conditions. ${ }^{[33]}$ Lignin conversion has been studied widely and especially recently. Various strategies including thermal decomposition, oxidation, hydrogenolysis, decarboxylation and decarbonylation were employed to convert lignin model compounds or real lignin into aromatics, solvents, liquid fuels, bioethanol or other valuable chemicals. [34-42]

Our group has mainly focused on lignin hydrogenolysis, oxidation and the further upgrading of intermediate compounds (Scheme 3). A novel bimetallic strategy to prepare superior hydrogenolysis catalysts for lignin model compounds and lignin hydrogenolysis were demonstrated. Twelve NiM (M represents another metal element) catalysts were synthesized from the metal chloride/nitrate precursor by $\mathrm{NaBH}_{4}$ reduction and PVP protection in water. ${ }^{[43,44]}$ These catalysts were evaluated in the hydrogenolysis of a $\beta-O-4$ model compound 2-phenoxy-1-phenylethanol in water (Fig. 3). Compared with single component Ni catalyst, significant promotional effects were observed for $\mathrm{NiAu}$, $\mathrm{NiRu}, \mathrm{NiRh}$ and NiPd catalysts, with remarkably enhanced activity without compromising selectivity towards monomeric compounds. Among them, the NiAu was the most special case because Au was completely ineffective for hydrogenolysis reaction. With the optimal $\mathrm{Ni}_{7} \mathrm{Au}_{3}$ catalyst, $87 \%$ of monomer yield could be realized at $130{ }^{\circ} \mathrm{C}$ for $1 \mathrm{~h}$ under 10 bar $\mathrm{H}_{2}$ with almost $100 \%$ conversion starting from $\beta-\mathrm{O}-4$ model compounds. Besides, organosolv lignin can be converted with over $14 \mathrm{wt} \%$ monomer yield at $170{ }^{\circ} \mathrm{C}$ for $12 \mathrm{~h}$. It was found that the particle size of bimetallic NPs was much smaller than the pure Ni NPs. Therefore, the formation process of $\mathrm{NiAu}$ catalysts was investigated by UV-Vis spectroscopy. The results indicated that the Au core formed initially and quickly and then acted as a promoter to facilitate the catalytic reduction of $\mathrm{Ni}$ and the growth of the core-shell NiAu bimetallic catalyst. The mechanism was investigated by both DFT calculations and control ex-

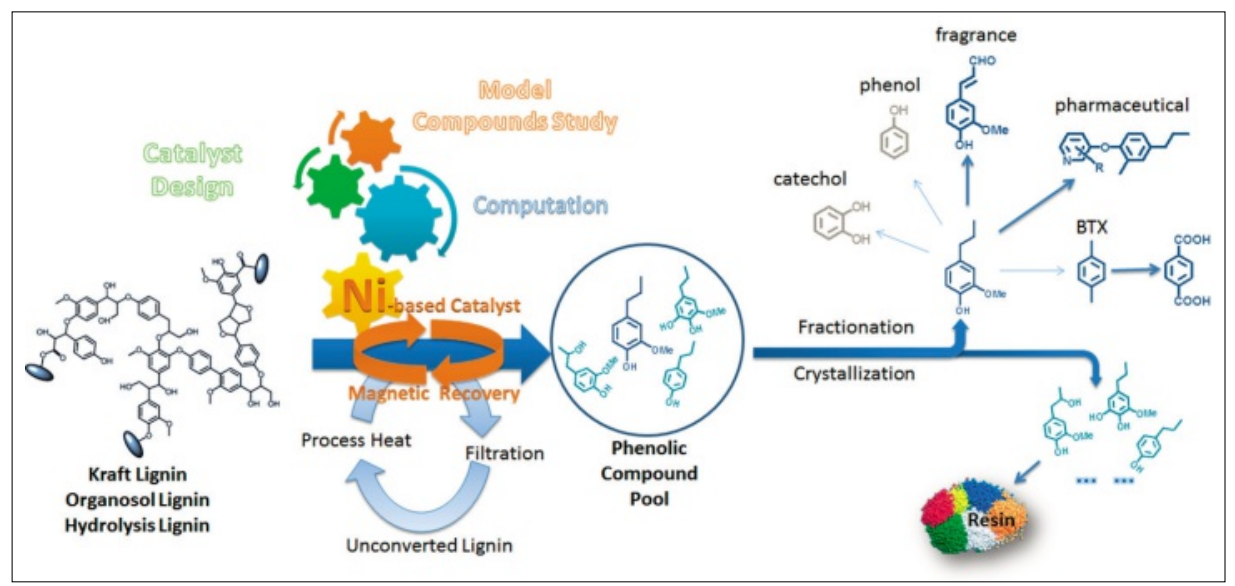

Scheme 3. A two-step protocol for lignin valorization into aromatic chemicals and materials, including 1) depolymerization of lignin into a pool of phenolic compounds; and 2) upgrading of phenol derivatives to end aromatic products. 


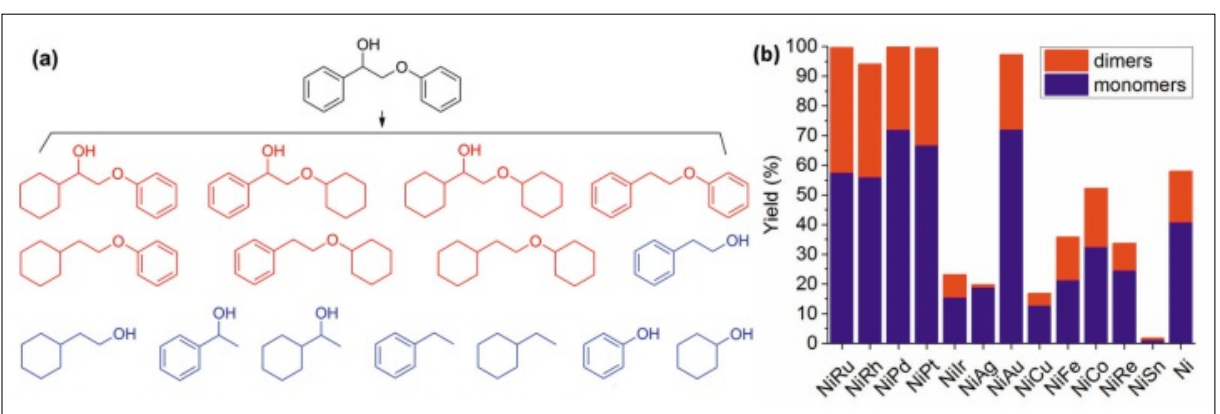

Fig. 3. (a) 15 Products identified after 2-phenoxy-1-phenylethanol hydrogenolysis; (b) dimer and monomer yields for pure $\mathrm{Ni}$ and bimetallic NiM catalysts $(\mathrm{Ni}: \mathrm{M}=4: 1)$. Reaction conditions: $0.22 \mathrm{mmol} 2$-phenoxy-1-phenylethanol, $3 \mathrm{~mL}$ freshly prepared aqueous solution containing 0.022 mmol metal and $0.44 \mathrm{mmol} P V P, 10$ bar $\mathrm{H}_{2}, 130{ }^{\circ} \mathrm{C}, 2.5 \mathrm{~h}$. Adapted from ref. [44] with permission from the Royal Society of Chemistry.

periments, suggesting that the promotional effect of $\mathrm{Au}$ to $\mathrm{Ni}$ was due to the combined size effect and electronic effects.

The hydrogenolysis of lignin or lignin model compounds by other bimetallic systems was further studied.[45] It was discovered that the presence of base could promote both the reaction activity and selectivity. Hydrogenolysis of $\beta-O-4$ compound 2-phenoxy-1-phenylethanol over $\mathrm{Ni}, \mathrm{Ni}_{7} \mathrm{Au}_{3}$ and $\mathrm{Ni}_{85} \mathrm{Ru}_{15}$ catalysts was investigated in the presence of $\mathrm{NaOH}$. $76.4 \%$ monomer yield was achieved by using $\mathrm{Ni}_{7} \mathrm{Au}_{3} \mathrm{NPs}$ and 2.7 equiv. $\mathrm{NaOH}$ at $100{ }^{\circ} \mathrm{C}$ for $2 \mathrm{~h}$ under 10 bar $\mathrm{H}_{2}$. At different $\mathrm{pH}$ values, the catalysts do not experience chemical or structure changes. Part of the reason for the enhanced performance can be ascribed to the improved solubility. At higher pHs, phenols exist as phenolates in water, which has a much higher solubility. Another factor is the inhibition of hydrogenation activity of metal catalysts by base. Further control experiments on toluene hydrogenation showed that a hindered coordination of the aromatic ring on the catalyst surface happened, slowing down the aromatic ring hydrogenation reaction. In addition, the influence of different base species was investigated. $\mathrm{LiOH}$ and $\mathrm{KOH}$ showed similar performance whereas organic bases such as $\mathrm{Et}_{3} \mathrm{~N}$ exhibited a negligible effect.

Besides the hydrogenolysis reaction, the oxidation of lignin/lignin model compound was also studied. Metal-free, highly-stable nitrogen-bearing graphene material $(\mathrm{LCN})$ has been employed as an efficient catalyst for five lignin model compound oxidation with tertbutyl hydroperoxide as the additive, to afford various aromatic chemicals such as aromatic aldehydes and acids as well as other organic chemicals in high yield.[46] The oxidation of real lignin has been attempted as well, resulting in the formation of a liquefied, low-molecular-mass oil. The mechanism has been studied by combining instrumental analysis, radical trapping experiments and kinetic investigation. The reaction shows a free-radical mechanism, starting from the benzylic $\mathrm{C}-\mathrm{H}$ or $\mathrm{C}-\mathrm{OH}$ bond activation and then the cleavage of the $\mathrm{C}_{\alpha}-\mathrm{C}_{\beta}$ or $\mathrm{C}_{\alpha}-\mathrm{O}$ bond, and lastly the oxidation of the intermediates.

\section{Chitin Conversion}

Compared to cellulose and lignin conversion, chitin conversion has been less explored and is still in a preliminary stage. Recent progress in the field will only be briefly described but a more detailed account will be published elsewhere. The conversion of $N$-acetyl glucosamine (NAG), chitin monomer, is less complex than chitin and the catalytic conversions were reported earlier. Pyrolysis of NAG was demonstrated in 1984, leading to various products with low selectivity. Since 2012, the catalytic and non-catalytic dehydration of NAG has been described affordpermission from the Royal Society of Chemistry. ing high yield of $N$-containing products such as 5-HMF, 3-acetamido-5-acetylfuran (3A5AF), Chromogen I, Chromogen III, 2-acetamido-3,6-anhydro-2-deoxyD-glucofuranose (3,6-anhydro-GNF) and 2-acetamido-3,6-anhydro-2-deoxy-Dmannofuranose (3,6-anhydro-MNF). ${ }^{47-49]}$ The oxidation of NAG into the corresponding amino acid by Au NPs has also been reported. ${ }^{[50,51]}$

Publications concerning direct chitin conversion were mostly published from 2009 to 2014. Initially, chemicals such as furans and organic acids were obtained. [52-54] Nevertheless, the biologically-fixed nitrogen was lost in the products. The dehydration of chitin was the first time that the concept of employing chitin as a nitrogen resource was demonstrated, by using boric acid and metal salts as additive and $N$-methyl-2-pyrrolidone (NMP) organic solvent.[55] The dehydration product $3 \mathrm{~A} 5 \mathrm{AF}$ could be obtained in one-step manner with $7.5 \%$ yield at $215^{\circ} \mathrm{C}$ for $2 \mathrm{~h}$. The work also shed light on the reaction mechanism by conducting poison tests and NMR studies. Afterwards, chitin liquefaction was realized by using sulfuric acid as the catalyst and ethylene glycol (EG) as the solvent. ${ }^{[56]} \mathrm{Up}$ to $75 \%$ of solid chitin was converted into liquids at $165{ }^{\circ} \mathrm{C}$ for $1.5 \mathrm{~h}$ with a total $30 \%$ yield of the major products hydroxyethyl-2-amino-2-deoxyhexopyranoside (HADP) and hydroxyethyl-2-acetamido-2-deoxyhexopyranoside (HAADP), which can be further converted into polymers such as resins and polyamides.

The hydrogenolysis of chitin monomer has been described very recently by employing supported metal catalysts in water, ${ }^{[57]}$ and the aim is to obtain useful

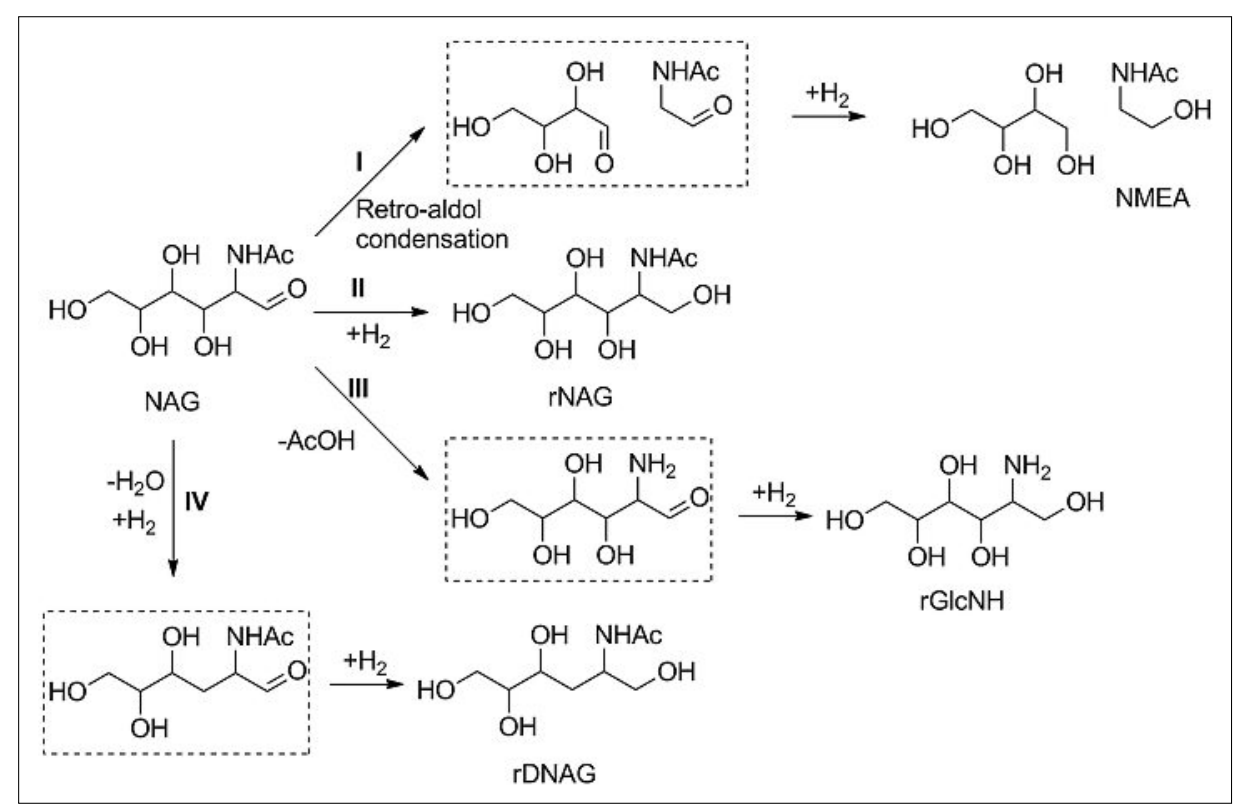

Scheme 4. The four parallel reaction pathways of NAG conversion. Reproduced from ref. [57] with 
amine/amide polyols. $\mathrm{Ru} / \mathrm{C}, \mathrm{Rh} / \mathrm{C}, \mathrm{Pd} / \mathrm{C}$ and $\mathrm{Pt} / \mathrm{C}$ were attempted with $\mathrm{Ru} / \mathrm{C}$ showing the best results. More than ten chemicals were identified on GC-MS and HPLC. By using $\mathrm{Ru} / \mathrm{C}, 8.7 \% \mathrm{~N}$-acetyl monoethanolamine (NMEA), $6.1 \% \mathrm{C}_{4}$ polyols, and $71.9 \% \quad \mathrm{C}_{6}$ polyols ( $N$-containing) could be obtained at $180{ }^{\circ} \mathrm{C}$ under 40 bar $\mathrm{H}_{2}$ for $1 \mathrm{~h}$ with $1 \mathrm{~mol} \%$ loading. The kinetic data showed that the formation of the major products proceeded in four parallel pathways, including retro-aldol condensation, dehydration/hydrogenation, deacetylation/ hydrogenation and direct hydrogenation (see Scheme 4). At higher reaction temperature, the hydrogenolysis to form smaller molecules such as NMEA was favored, whereas direct hydrogenation of NAG was favored at lower temperature.

\section{Conclusion}

This short review gives a brief introduction of the research on renewable carbon resources utilization with a focus on the recent progress relevant to our group. Lignocellulosic and chitin biomass materials are low cost, green, sustainable and abundant carbon resources, which are promising alternatives to replace fossil oils for the production of sustainable chemicals. The transformations of these materials are challenging because of the structural complexity and instability of biomass. The understanding of the reaction nature and pathway of these resources towards useful chemicals are necessary, and it is crucial to envisage new possibilities and routes for the production of various chemicals to build up the product chains.

\section{Acknowledgement}

We thank National University of Singapore and the MOE Tier-1 project (WBS: R-279-000438-112) for the financial support.

Received: January 10, 2015
[1] A. Corma, S. Iborra, A. Velty, Chem. Rev. 2007, 107, 2411.

[2] G. W. Huber, S. Iborra, A. Corma, Chem. Rev. 2006, 106, 4044.

[3] J. R. Rostrup-Nielsen, Science 2005, 308, 1421.

[4] A. Fukuoka, P. L. Dhepe, Angew. Chem. Int. Ed. 2006, 45,5161

[5] R. Rinaldi, F. Schüth, ChemSusChem 2009, 2, 1096.

[6] M. Stöcker, Angew. Chem. Int. Ed. 2008, 47, 9200.

[7] C.-H. Zhou, X. Xia, C.-X. Lin, D.-S. Tong, J. Beltramini, Chem. Soc. Rev. 2011, 40, 5588.

[8] C. Liu, H. Wang, A. M. Karim, J. Sun, Y. Wang, Chem. Soc. Rev. 2014, 43, 7594.

[9] M. Hara, Energ. Environ. Sci. 2010, 3, 601.

[10] Y.-B. Huang, Y. Fu, Green Chem. 2013, 15, 1095.

[11] F. M. Kerton, Y. Liu, K. W. Omari, K. Hawboldt, Green Chem. 2013, 15, 860

[12] M. Rinaudo, Prog. Polym. Sci. 2006, 31, 603.

[13] C. K. S. Pillai, W. Paul, C. P. Sharma, Prog. Polym. Sci. 2009, 34, 641

[14] M. Saidi, F. Samimi, D. Karimipourfard, T. Nimmanwudipong, B. C. Gates, M. R. Rahimpour, Energ. Environ. Sci. 2014, 7, 103.

[15] X. Chen, N. Yan, Catal. Surv. Asia 2014, DOI: 10.1007/s10563-014-9171-1, 1-13.

[16] N. Yan, P. J. Dyson, Curr. Opin. Chem. Engin. 2013, 2, 178.

[17] A. M. Ruppert, K. Weinberg, R. Palkovits, Angew. Chem. Int. Ed. 2012, 51, 2564

[18] P. L. Dhepe, A. Fukuoka, ChemSusChem 2008, 1,969 .

[19] R. Rinaldi, F. Schuth, Energ. Environ. Sci. $\mathbf{2 0 0 9}, 2,610$

[20] K.-i. Shimizu, A. Satsuma, Energ. Environ. Sci. 2011, $4,3140$.

[21] M. E. Zakrzewska, E. Bogel-Lukasik and R. Bogel-Lukasik, Chem. Rev. 2011, 111, 397.

[22] A. Boisen, T. B. Christensen, W. Fu, Y. Y. Gorbanev, T. S. Hansen, J. S. Jensen, S. K. Klitgaard, S. Pedersen, A. Riisager, T. Ståhlberg, J. M. Woodley, Chem. Engin. Res. Design 2009, 87, 1318.

[23] A. J. J. E. Eerhart, A. P. C. Faaij, M. K. Patel, Energ. Environ. Sci. 2012, 5, 6407.

[24] J. D. Scholten, B. C. Leal, J. Dupont, ACS Catal. 2011, 2, 184

[25] S. Siankevich, Z. Fei, R. Scopelliti, G. Laurenczy, S. Katsyuba, N. Yan, P. J. Dyson, ChemSusChem 2014, 7, 1647.

[26] H. Zhao, J. E. Holladay, H. Brown, Z. C. Zhang, Science 2007, 316, 1597.

[27] M. Bicker, J. Hirth, H. Vogel, Green Chem. 2003, 5,280 .

[28] F. Salak Asghari, H. Yoshida, Ind. Eng. Chem. Res. 2006, 45, 2163.

[29] N. Jiang, R. Huang, W. Qi, R. Su, Z. He, Bioenerg. Res. 2012, $5,380$.

[30] E. L. S. Ngee, Y. Gao, X. Chen, T. M. Lee, Z. Hu, D. Zhao, N. Yan, Ind. Eng. Chem. Res. 2014, 53, 14225 .
[31] S. Siankevich, G. Savoglidis, Z. Fei, G. Laurenczy, D. T. L. Alexander, N. Yan, P. J. Dyson, J. Catal. 2014, 315, 67.

[32] S. Ghazali-Esfahani, H. Song, E. Paunescu, F. D. Bobbink, H. Liu, Z. Fei, G. Laurenczy, M. Bagherzadeh, N. Yan, P. J. Dyson, Green Chem. 2013, 15,1584 .

[33] E. E. Harris, J. D'Ianni, H. Adkins, J. Am. Chem. Soc. 1938, 60, 1467.

[34] K. Barta, G. R. Warner, E. S. Beach, P. T. Anastas, Green Chem. 2014, 15, 191.

[35] Y. Ren, M. Yan, J. Wang, Z. C. Zhang, K. Yao, Angew. Chem. Int. Ed. 2013, 52, 12674.

[36] V. Molinari, C. Giordano, M. Antonietti, D. Esposito, J. Am. Chem. Soc. 2014, 136, 1758.

[37] D. J. Rensel, S. Rouvimov, M. E. Gin, J. C. Hicks, J. Catal. 2013, 305, 256.

[38] M. J. Climent, A. Corma, S. Iborra, Green Chem. 2014, 16, 516

[39] W. Mu, H. Ben, A. Ragauskas, Y. Deng, Bioenerg. Res. 2013, 6, 1183.

[40] G. Chatel, R. D. Rogers, ACS Sustainable Chem. Eng. 2013, 2, 322.

[41] P. Azadi, O. R. Inderwildi, R. Farnood, D. A. King, Renew. Sust. Energ. Rev. 2013, 21, 506.

[42] M. P. Pandey, C. S. Kim, Chem. Engin. Technol. 2011, 34, 29.

[43] J. Zhang, J. Teo, X. Chen, H. Asakura, T. Tanaka, K. Teramura, N. Yan, ACS Catal. 2014, 4, 1574 .

[44] J. Zhang, H. Asakura, J. v. Rijn, J. Yang, P. Duchesne, B. Zhang, X. Chen, P. Zhang, M. Saeys, N. Yan, Green Chem. 2014, 16, 2432.

[45] H. Konnerth, J. Zhang, D. Ma, M. H. G. Prechtl, N. Yan, Chem. Eng. Sci. 2015, 123, 155.

[46] Y. Gao, J. Zhang, X. Chen, D. Ma, N. Yan, ChemPlusChem 2014, 79, 825.

[47] M. Osada, K. Kikuta, K. Yoshida, K. Totani, M. Ogata, T. Usui, Green Chem. 2013, 15, 2960.

[48] K. W. Omari, L. Dodot, F. M. Kerton, ChemSusChem 2012, 5, 1767.

[49] M. W. Drover, K. W. Omari, J. N. Murphy, F. M. Kerton, RSC Adv. 2012, 2, 4642

[50] Y. Ohmi, S. Nishimura, K. Ebitani, ChemSusChem 2013, 6, 2259.

[51] G. S. Dhillon, S. K. Brar, J. R. Valero, M. Verma, Bioproc. Biosyst. Eng. 2011, 34, 1017.

[52] Y. Wang, C. M. Pedersen, T. Deng, Y. Qiao, X. Hou, Bioresource Technol. 2013, 143, 384.

[53] K. W. Omari, J. E. Besaw, F. M. Kerton, Green Chem. 2012, 14, 1480.

[54] M. Mascal, E. B. Nikitin, ChemSusChem 2009, 2,859 .

[55] X. Chen, S. L. Chew, F. M. Kerton, N. Yan, Green Chem. 2014, 16, 2204

[56] Y. Pierson, X. Chen, F. D. Bobbink, J. Zhang, N. Yan, ACS Sustainable Chem. Eng. 2014, 2, 2081.

[57] F. D. Bobbink, J. Zhang, Y. Pierson, X. Chen, N. Yan, Green Chem. 2015, 17, 1024 